\title{
Formação docente em Ensino Religioso em curso de Pedagogia no Rio Grande do Sul
}

\author{
Teacher training on Religious Education in the Pedagogy \\ course program in Rio Grande do Sul
}

\section{Remí Klein}

Doutor em Teologia na Área de Religião e Educação, docente na Faculdade EST e na Universidade Jesuíta do Rio Grande do Sul (Unisinos), São Leopoldo, RS - Brasil, e-mail: remiklein@terra.com.br

\section{Resumo}

O texto visa a socializar projeto de pesquisa sobre o Ensino Religioso na formação docente. Parte do pressuposto da importância da capacitação em Metodologia de Ensino Religioso nos cursos de licenciatura em Pedagogia, visto que, pela legislação vigente em nível nacional e estadual (RS), não é exigida nenhuma formação específica, além da habilitação docente propriamente dita, para lecionar a referida disciplina na educação infantil e nos anos iniciais do ensino fundamental. Abarca o embasamento legal sobre o assunto e o confronta com uma pesquisa de campo, envolvendo a própria prática docente, bem como a atuação de outros docentes e a participação de discentes na referida disciplina pedagógica em cursos de licenciatura em Pedagogia em instituições de ensino superior na região metropolitana de Porto Alegre.

Palavras-chave: Ensino Religioso. Legislação. Formação docente. Metodologia. Práxis educativa. 


\section{Abstract}

The text aims to socialize the research project on Religious Education into teacher training programs. It stems from the presupposition that training in the methodology of Religious Education is important in the teacher graduation programs in Pedagogy, bearing in mind that, in current legislation on the national and state (RS) levels, no specific training is required, besides the teacher graduation itself, to teach the referred subject in pre-school education and in the first years of grade school. It covers the legal bases on the subject and confronts it with a field research, involving teaching practice itself, as well as the action of other teachers and the participation of students in the referred pedagogical subject in the teacher graduation programs in Pedagogy in Higher Education Institutions located in the metropolitan region of Porto Alegre.

Keywords: Religious Education. Legislation. Teacher graduation. Methodology. Educational praxis.

\section{Introdução}

[...] é impossível ensinarmos conteúdos sem saber como pensam os alunos no seu contexto real, na sua cotidianidade. Sem saber o que eles pensam independentemente da escola para que os ajudemos a saber melhor o que já sabem, de um lado, e, de outro, a partir daí, ensinar-lhes o que ainda não sabem (FREIRE, 1993, p. 105).

Nessas palavras de Paulo Freire, em epígrafe, evidencia-se quão importante no processo educativo-religioso, bem como no processo educativo em geral, é partir do conhecimento prévio de nossos educandos, sejam eles estudantes crianças e jovens ou docentes em sua formação inicial e continuada. Com este pressuposto e princípio pedagógico trago uma amostra de um exercício de diagnóstico e integração vinculado à Atividade Acadêmica Sujeitos, Espaços e Tempo: Ensino Religioso do curso de Pedagogia na Unisinos. Realizo este 'entrejogo' desde a minha pesquisa de campo com vistas à tese de doutorado em Teologia, na Área de Concentração de Religião e Educação, no Programa de Pós-Graduação em Teologia da Faculdades EST, entre 2000 e 2004, em estreita vinculação com a minha docência e voltado à formação docente. 
Como proposta metodológica, utilizo um jogo intitulado Minha história - tua história e o resgate de memoriais descritivo-analíticos. A meu ver, tais metodologias de pesquisa participante possibilitam aos estudantes em sua formação docente pensarem sobre o seu próprio processo educativo-religioso como crianças e jovens, enquanto educandos, para, a partir daí, melhor se assumirem e se prepararem como educadores que estão sendo hoje ou que serão um dia, com vistas, em especial, à sua atuação docente no Ensino Religioso nas escolas.

Como referenciais teóricos para esta atividade, apoio-me especialmente na etnografia e na cartografia ${ }^{1}$. Tomo a liberdade de fazer um jogo de palavras entre etnografia e cartografia e, no intuito de aproximá-las e de integrá-las em minha proposta, uso o termo 'etnocartografia'. A tese, defendida em 2004, ficou assim intitulada: Histórias em jogo: rememorando e ressignificando o processo educativo-religioso sob um olhar etnocartográfico.

\section{Histórias 'em jogo'}

Para introduzir o jogo Minha história - tua história e o memorial descritivo-analítico com os estudantes, sob um olhar 'etnocartográfico', conto-lhes geralmente uma história infantil de Mem Fox, intitulada Guilherme Augusto Araújo Fernandes. Fala sobre um menino com esse nome que morava ao lado de um asilo de velhos (sic) e que gostava de ouvir as histórias que lhe contavam as pessoas idosas que ali viviam. Ficou intrigado ao ouvir de seus pais, certo dia, que Dona Antônia Maria Diniz Cordeiro perdera a sua memória. Era a pessoa de quem ele mais gostava porque ela também tinha quatro nomes como ele. Passou então a procurar memórias para Dona Antônia e, a cada objeto que lhe levava, ela passava a se recordar de fatos acontecidos em sua vida. O livro encerra assim: "Os dois sorriram e sorriram, pois toda a memória perdida de Dona Antônia tinha sido encontrada por um menino que não era tão velho assim" (FOX, 1995, p. 24-30).

1 Sobre etnografia ver ANDRÉ, M. E. D. A. de. Etnografia da prática escolar. 4. ed. Campinas: Papirus, 1995; sobre cartografia ver ROLNIK, S. Cartografia sentimental: transformações contemporâneas do desejo. São Paulo: Estação Liberdade, 1989. 
Renate Gierus (2004, p. 50), num artigo intitulado CorpOralidade História Oral e corpo, refere a esta mesma história ao falar sobre o poder da memória na historiografia feminista, destacando dois termos: a reconstrução e o empoderamento, que, a meu ver, são aspectos igualmente fundamentais na formação docente voltada ao processo educativo-religioso:

Dona Antônia estava reconstruindo seu passado, lembrando vários momentos de sua vida. Assim também o menino Guilherme Augusto: ao escolher o que levaria para dona Antônia, também ele foi reconstruindo a sua vida. E dona Antônia empodera-se. Ela participa do poder da vida, e suas potencialidades vêm à tona. As suas memórias foram novamente encontradas.

O resgate de nossas memórias, o seu registro e a reflexão sobre elas constituem a nossa identidade pessoal e também profissional (docente), como vemos nas palavras de Madalena Freire Weffort et al. (1996, p. 9):

Todas estas lembranças quando resgatadas, socializadas entre outras e, assim, apropriadas, ganham status de memória. Memória que alicerça a consciência histórica, política e pedagógica desse sujeito. O desafio é formar, informando e resgatando num processo de acompanhamento permanente, um educador que teça seu fio para apropriação de sua história, pensamento, teoria e prática.

Falo em histórias 'em jogo' e em novos olhares 'em formação', no sentido de repensarmos o nosso processo de formação docente em estreita vinculação entre o ensino e a pesquisa, num confronto entre a teoria e a prática, tanto na formação inicial como na formação continuada, como vemos no testemunho de vida do educador Paulo Freire (1991, p. 58): "A gente se forma como educador, permanentemente, na prática e na reflexão sobre a prática".

Vejamos, a seguir, alguns extratos de memoriais descritivo-analíticos postados no fórum de discussão na plataforma moodle, a partir do jogo vivenciado na aula de $3 / 3 / 2011^{2}$ e que evidenciam o quanto esta

2 Todos os memoriais descritivo-analíticos a seguir foram acessados e extraídos do fórum de discussão da plataforma moodle da Unisinos referente à Atividade Acadêmica Sujeitos, espaços e tempos: Ensino Religioso. Disponível em: <http://www.moodle.unisinos.br/mod/form/discuss.php?=164371>. Acesso em: 19 jul. 2011. 
experiência é significativa para os estudantes em seu processo de formação docente:

O jogo da aula passada foi muito legal! No início achei esquisito ter que desenhar bolinhas, retângulos, quadrados... mas no desenvolver do jogo e consequentemente as novidades, as coisas extraordinárias que os colegas iam contando, a dinâmica foi bem aceita. [...] Bom... é muito bom relembrar e pensar que naqueles momentos passei grandes momentos e com grandes pessoas. Como eu queria que voltasse ${ }^{3} .$.

Achei muito legal a forma como foi trabalhado o resgate de nossas lembranças religiosas. O jogo na verdade foi muito tranquilo e trabalhou de uma forma muito sutil a religiosidade de cada um, sem interferir no que cada um pensa. [...] Discutir em sala de aula sempre foi uma questão complicada, pois nem sempre conseguimos respeitar o que o outro pensa e a escola por sua vez não valoriza a matéria "Ensino Religioso". Mas, após fazer esta atividade, onde contamos como foram nossas histórias de uma forma tão agradável, pensei que podemos trabalhar em sala de aula sim, respeitando o que cada um pensa ${ }^{4}$.

De modo geral, percebe-se que esta proposta de pesquisa etnocartográfica vinculada à docência foi uma vivência significativa para os estudantes, resgatando, por meio do jogo e do memorial, as suas histórias 'em jogo', repensando, assim, a sua própria história de vida e, em especial, o seu próprio processo educativo-religioso, bem como integrando o ensino acadêmico e a pesquisa de campo, a teoria e a prática, sob um olhar 'etnocartográfico', com vistas à sua formação docente. Trata-se, pois, de um 'entrejogo' de memórias na formação docente. Neste sentido, recorro novamente a Paulo Freire (1993, p. 102) para evidenciar o quanto esta experiência pode gerar novos olhares 'em formação':

Entre nós a prática no mundo, na medida em que começamos não só a saber que vivíamos mas o saber que sabíamos e que, portanto, podíamos saber mais, iniciou o processo de gerar o saber da própria prática. [...] Foi a prática que fundou a fala sobre ela e a consciência dela, prática.

3 Extrato do memorial descritivo-analítico de uma estudante de Pedagogia, Unisinos, 2011/1.

4 Extrato do memorial descritivo-analítico de uma estudante de Pedagogia, Unisinos, 2011/1. 
São histórias 'em jogo' que nos constituem como pessoas e como educadores. Neste sentido, transcrevo dois extratos de memoriais de estudantes de Pedagogia com suas reflexões sobre a formação e atuação docentes em relação ao processo educativo-religioso:

Foi muito interessante fazer este jogo em aula, pois me trouxe lembranças até então bastante adormecidas. Ele me fez pensar sobre a minha construção educativo-religiosa e perceber o quanto ela se deu, muito mais em casa, com meus pais, do que na escola ou em ambientes religiosos, como igreja, a catequese, que foram os mais abordados no grupo em que eu estava. Nesse contexto também pude confrontar minhas lembranças com as das colegas e, para minha surpresa, apenas eu, no jogo, não era da religião Católica. Isso me chamou atenção, pelo fato de hoje existir mais liberdade para escolhermos a religião que mais nos completa, porém, sei que muitos apenas seguem a religião que foi de seus pais. Não tenho nada contra isso, mas penso que as pessoas são diferentes e únicas e, por isso, buscam coisas diferentes para suas vidas, portanto, na religiosidade não deveria ser diferente, não apenas seguir algo por influências familiares. Acredito que a família tem um papel fundamental em apresentar e formar a identidade religiosa de seus filhos, mas sem que isso seja determinar qual religião que eles irão seguir ${ }^{5}$. [...]

Achei muito importante o resgate de nossas memórias e a reflexão que fizemos após cada colega contar um pouco sobre a sua história e também de terem a oportunidade de escutar a nossa. O jogo Minha história-tua história nos fez regressar, voltar no passado, relembrar acontecimentos marcantes vividos por nós e que, de repente, nunca tinham sido contados até então. É bom reviver esses momentos, essas lembranças são especiais em nossas vidas. Foi de extrema importância expressar nossos sentimentos, falar sobre as nossas memórias religiosas. Isso nos faz pensar, refletir, analisar o nosso processo educativo-religioso. Através desse jogo, da ideia central do jogo, podemos nos dar conta, nós e os nossos alunos, que todos possuímos uma história, uma história religiosa pessoal, que deve ser ouvida e respeitada por todos, seja qual for 6 .

A partir desse enfoque sobre histórias 'em jogo', com vistas a exercitar novos olhares 'em formação', no processo educativo-religioso, trago ainda uma palavra de Rubem Alves (1995a, p. 33-34) sobre a formação docente:

5 Extrato de memorial descritivo-analítico de estudante de Pedagogia, Unisinos, 2011/1.

6 Extrato de memorial descritivo-analítico de estudante de Pedagogia, Unisinos, 2011/1. 
Não sei como preparar o educador. Talvez porque isto não seja nem necessário, nem possível... É necessário acordá-lo. [...] Basta que os chamemos do seu sono, por um ato de amor e coragem. E, talvez, acordados, repetirão o milagre da instauração de novos mundos.

\section{Novos olhares 'em formação'}

A verdade da infância não está no que dizemos dela, mas no que ela nos diz no próprio acontecimento de sua aparição entre nós, como algo novo. $\mathrm{E}$, além disso, tendo-se em conta que, ainda que a infância nos mostre uma face visível, conserva também um tesouro oculto de sentido, o que faz com que jamais possamos esgotá-la (LARROSA, 2001, p. 195).

Iniciando este subtítulo sobre novos olhares 'em formação' com uma epígrafe de Jorge Larrosa, quero expressar a perspectiva com que desenvolvi a minha pesquisa e a elaboração da minha tese, no sentido de aproximar-me, por meio da narração de histórias marcantes, da perspectiva de discentes em sua formação docente e também de crianças para, assim, rememorar e ressignificar o seu processo educativo-religioso, ciente de que este olhar não basta ser acadêmico e pedagógico, mas que precisa apreender e captar o cotidiano e o invísível, ou seja, ser 'etnocartográfico'. O conhecimento torna-se, assim, autobiográfico e existencial. Falo, por isso, neste subtítulo, em novos olhares 'em formação', num duplo sentido: de exercitar um novo olhar educativo a partir da perspectiva dos próprios discentes em sua formação docente e das crianças em seu processo educativo-religioso e de integrar o ensino com a pesquisa, a partir das histórias 'em jogo'. Nesse sentido, Maria Isabel da Cunha (1998, p. 39) refere-se ao trabalho com narrativas no ensino e na pesquisa ao afirmar:

Trabalhar com narrativas na pesquisa e/ou no ensino é partir para a desconstrução/construção das próprias experiências, tanto do professor/pesquisador como dos sujeitos da pesquisa e/ou do ensino. Exige que a relação dialógica se instale criando uma cumplicidade de dupla descoberta. Ao mesmo tempo que se descobre no outro, os fenômenos revelam-se em nós.

Nessa atividade desenvolvida por meio do jogo e da elaboração dos memoriais descritivo-analíticos com estudantes em sua formação docente 
sobre o seu processo educativo-religioso, tive muitos depoimentos neste sentido apontado por Maria Isabel da Cunha quanto às "narrativas como explicitadoras e como produtoras de conhecimento" (1998, p. 37), como se evidencia no extrato dos seguinte memorial referente ao jogo Minha história - tua história, com vistas ao processo educativo-religioso das crianças:

[...] gostei muito da proposta da nossa primeira aula, pois, assim como nós professoras utilizamos o jogo na sala de aula para propiciar um ambiente mais lúdico para as crianças, fazendo com que elas demonstrem suas vivências e opiniões de uma forma muito mais espontânea, nós também tivemos a oportunidade de relembrar fatos marcantes em nossa vida em relação à religião e pudemos conhecer as histórias das(os) colegas? ${ }^{7}$.

Evidencia-se nesses extratos de memoriais, a importância da construção social do conhecimento, para, a partir da realidade de vida dos educandos, do seu imaginário religioso e das suas memórias, ressignificar o seu processo educativo-religioso. E, neste sentido, o jogo Minha história - tua história certamente possibilita, de uma forma lúdica e pedagógica, o resgate dos conhecimentos prévios dos educandos, oportunizando um processo interativo e existencial de construção de conhecimento religioso, a partir das suas histórias 'em jogo'.

Achei muito legal a dinâmica da primeira aula, pois com ela pude relembrar a minha história e saber um pouco da história dos meus colegas. Tinha coisas que tive que pensar antes de desenhar que já estavam esquecidas, pois nunca mais havia falado sobre esse assunto e me fez pensar ${ }^{8}$. [...]

Achei o jogo instigante, nos fez recordar de nossas infâncias, que no meu caso tinha fatos que nunca tinha parado para pensar. Observei que o jogo aproxima as pessoas que estão participando porque, ao mesmo tempo em que você conta a sua história, você escuta o outro. O ponto negativo é que podemos notar que ainda existem pessoas com preconceitos e ideias pré-fixadas. Como o professor citou, devemos nos fixar na identidade e na alteridade, ter consciência de que vivemos em sociedade e que cada indivíduo tem uma cultura que não é única, mas que deve ser respeitada por seus semelhantes ${ }^{9}$.

\footnotetext{
Extrato do memorial descritivo-analítico de uma estudante de Pedagogia, Unisinos, 2011/1.

8 Extrato do memorial descritivo-analítico de uma estudante de Pedagogia, Unisinos, 2003.

9 Extrato do memorial descritivo-analítico de uma estudante de Pedagogia, Unisinos, 2011/1.
} 
Ao falarmos em novos olhares 'em formação', não se trata, em primeiro lugar, de uma questão de repensar o que ensinar ou o que saber, ou seja, não se trata só de uma questão de conhecimento religioso. A pergunta "O que saber?" nunca está separada de uma outra pergunta fundamental e precedente: O que os educandos devem ser ou se tornar? Essa concepção de currículo e de processo educativo, abrangendo não só o saber e o saber fazer, mas também o ser e o conviver, está muito bem expressa no relatório da Unesco, de 1996, ao se referir aos quatro pilares da educação (DELORS et al., 1998, p. 89). Nesse sentido, conforme Tomaz Tadeu da Silva (1999, p. 15), toda concepção de currículo está estreitamente inter-relacionada com o tipo de conhecimento (saber) e, mais ainda, com o tipo de ser humano que se quer formar:

No fundo das teorias do currículo está, pois, uma questão de 'identidade' ou de 'subjetividade'. Se quisermos recorrer à etimologia da palavra 'currículo', que vem do latim 'curriculum', 'pista de corrida', podemos dizer que no curso dessa 'corrida' que é o currículo acabamos por nos tornar o que somos.

De acordo com Silva (1999, p. 16), além de uma questão de conhecimento, o currículo é também uma questão de identidade, além de uma questão de poder, pois "[...] privilegiar um tipo de conhecimento é uma operação de poder". Conforme Rubem Alves (1995a, p. 115), trata-se de relações de saber, poder e sabor. Para tal, o referido autor nos provoca com uma definição de Roland Barthes: "Sapientia: nenhum poder, um pouco de saber, o máximo de sabor..." E, na sua estória O currículo dos urubus, Rubem Alves (1995b, p. 67) conclui: "Talvez, para se repensar a educação e o futuro da Ciência, devêssemos começar não dos currículos-cardápios, mas do desejo do corpo que se oferece à educação. É isto: começar do desejo..." Uma pedagogia do corpo!

Por isso, a questão central ou precedente na discussão sobre o processo educativo-religioso em termos de novos olhares 'em formação' deveria priorizar não só o saber e o fazer, mas, acima de tudo, o ser e o conviver, ou seja, uma questão da identidade e de alteridade, de relacionamento consigo mesmo, com os outros, com a natureza e com a Transcendência, pois somos seres relacionais e a nossa religiosidade, por conseguinte, também é relacional, conforme Paul Tillich (1974, p. 5) e James W. Fowler (1992, p. 27) e como se evidencia no seguinte memorial: 
[...] senti certa dificuldade em relembrar experiências religiosas marcantes neste aspecto, o que atribuo ao afastamento que tenho hoje das instituições ou rituais religiosos. $\mathrm{O}$ mágico do jogo que fizemos em sala de aula foi justamente resgatar nossas experiências principalmente através da experiência do outro, onde a cada relato de algum colega despertava fatos adormecidos em minha memória. Não que estas pessoas ou acontecimentos não sejam importantes, mas ao longo do tempo, sem percebermos, deixamos muito da nossa história para trás. [...] Acima de tudo, creio no respeito à crença alheia e sinto que há muito mais para ser discutido no sentido de formação do ser humano nas aulas de Ensino Religioso do que a forma tendenciosa de ensinar religião que vemos hoje nas escolas ${ }^{10}$.

Os educandos aprendem com o jogo. Eles não aprendem apenas conteúdos religiosos, mas aprendem, acima de tudo, a conhecerem-se e também uns aos outros. Eles aprendem uns com os outros. Eles aprendem conosco e nós aprendemos com eles. A partir disso e a partir deles, aprendemos a exercitar novos olhares em nossa formação e atuação docente, como muito bem o expressa o seguinte extrato de um memorial de uma estudante:

Fiquei bem impressionado com a ludicidade com que foi tratado um tema que muitas vezes é encarado com tanta complexidade. Através do jogo consegui relembrar o processo educativo-religioso que tive. [...] A família tem a tarefa de dar uma base religiosa para as crianças, porém observo que a dificuldade de conviver com a diversidade religiosa desencadeia nos preconceitos que são passados de geração para geração. Devido a isso, a escola possui um papel fundamental, através do Ensino Religioso, para que se construam saberes que refletirão num convívio com a diversidade ${ }^{11}$.

\section{Considerações finais}

Por meio do jogo Minha história - tua história, os educandos reconstroem suas histórias 'em jogo' e se apropriam delas. Este é o grande desafio para nós, enquanto docentes e estudantes em formação docente, em relação ao processo educativo-religioso de nossos educandos: o de

\footnotetext{
10 Extrato do memorial descritivo-analítico de uma estudante de Pedagogia, Unisinos, 2011/1.

11 Extrato de memorial descritivo-analítico de estudante de Pedagogia, Unisinos, 2011/1.
} 
exercitarmos, a partir das nossas histórias, novos olhares 'etnocartográficos' como companheiros, facilitadores e mediadores, como muito bem o expressa Rubem Alves (1995a, p. 33): "Um educador [...] é um fundador de mundos, mediador de esperanças, pastor de projetos". Somos todos, enfim, histórias 'em jogo' e, no processo educativo (em geral e não só religioso), almejamos que, a partir das histórias lidas, ouvidas e vividas, os nossos educandos se tornem cada vez mais sujeitos e protagonistas da sua própria história, como o expressa muito bem o poema de Maria Dinorah (1986, p. 40), intitulado Quando eles souberem:

Os meninos que brincam, talvez não saibam, não, que há meninos na luta por um pouco de pão.

Os meninos que estudam, o fazem sem notar que há meninos sonhando com poder estudar.

Há meninos com tudo

a viver muito bem, que talvez não entendam por que tantos não têm.

E há meninos vivendo o momento da paz, sem sequer perceberem do que a guerra é capaz.

Mas, quando eles souberem, tudo isso vai passar, pois está nas crianças

o poder de mudar. 


\section{Referências}

ALVES, R. Conversas com quem gosta de ensinar. São Paulo: ARS Poética, 1995a.

ALVES, R. Estórias de quem gosta de ensinar. São Paulo: ARS Poética, 1995 b. ANDRÉ, M. E. D. A. de. Etnografia da prática escolar. 4. ed. Campinas: Papirus, 1995.

BRANDÃO, C. R. (Org.). Pesquisa participante. 4. ed. São Paulo: Brasiliense, 1984.

CUNHA, M. I. da. 0 professor universitário na transição de paradigmas. Araraquara: JM Editora, 1998.

DELORS, J. et al. (Org.). Educação: um tesouro a descobrir - Relatório para a Unesco da Comissão Internacional sobre educação para o século XXI. 2. ed. São Paulo: Cortez; Brasília: MEC; Unesco, 1998.

DINORAH, M. Panela no fogo, barriga vazia. São Paulo: L\&PM, 1986.

FOWLER, J. Estágios da fé. São Leopoldo: Sinodal, 1992.

FOX, M. Guilherme Augusto Araújo Fernandes. São Paulo: Brinque-Book, 1995.

FREIRE, P. A educação na cidade. São Paulo: Cortez, 1991.

FREIRE, P. Professora sim, tia não: cartas a quem ousa ensinar. São Paulo: Olho D’Água, 1993.

FREIRE, P.; GUIMARÃES, S. Aprendendo com a própria história I. Rio de Janeiro: Paz e Terra, 1987.

FREIRE, P.; GUIMARÃES, S. Aprendendo com a própria história II. Rio de Janeiro: Paz e Terra, 2000. 
GIERUS, R. CorpOralidade: história oral e corpo. In: STRÖHER, M. J. et al. (Org.). À flor da pele: ensaios sobre gênero e corporeidade. São Leopoldo: Sinodal; CEBI, 2004. p. 37-51.

KLEIN, R. Histórias em jogo: rememorando e ressignificando o processo educativo-religioso sob um olhar etnocartográfico. 2004. Tese (Doutorado em Religião e Educação) - Escola Superior de Teologia Instituto Ecumênico de Pós-Graduação em Teologia, São Leopoldo, 2004.

LARROSA, J. Pedagogia profana: danças, piruetas e mascaradas. Tradução de Alfredo Veiga-Neto. 4. ed. Belo Horizonte: Autêntica, 2001.

MEMORIAIS descritivo-analíticos da Atividade Acadêmica Sujeitos, Espaços e Tempos: Ensino Religioso do curso de Pedagogia da Universidade do Vale do Rio dos Sinos - Ed. Unisinos. São Leopoldo, RS, 2011. Disponível em: <http://www. moodle.unisinos.br/mod/form/discuss.php?=164371>. Acesso em: 19 jul. 2011. ROLNIK, S. Cartografia sentimental: transformações contemporâneas do desejo. São Paulo: Estação Liberdade, 1989.

SILVA, T. T. da. Documentos de identidade: uma introdução às teorias de currículo. Belo Horizonte: Autêntica, 1999.

TILLICH, P. Dinâmica da fé. São Leopoldo: Sinodal, 1974.

WEFFORT, M. F. et al. Observação, registro, reflexão: instrumentos metodológicos I. 2. ed. São Paulo: Espaço Pedagógico, 1996.

Recebido: 28/09/2011

Received: 09/28/2011

Aprovado: 01/03/2012

Approved: 03/01/2012 